\title{
Unusual location of lichen striatus in an adult patient
}

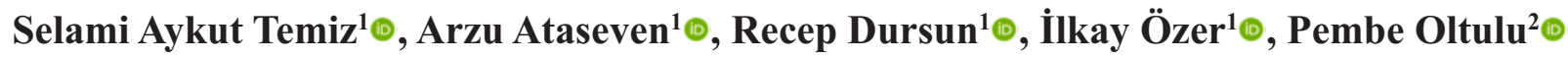 \\ ${ }^{1}$ Department of of Dermatology, Necmettin Erbakan University Meram School of Medicine, Konya, Turkey \\ ${ }^{2}$ Department of Pathology, Necmettin Erbakan University Meram School of Medicine, Konya, Turkey
}

DOI: 10.18621 /eurj.395069

\begin{abstract}
Lichen striatus is a rare inflammatory dermatosis that influences mostly children, being rare reports in adults. The pathogenesis is unknown. In addition, lichen striatus is demonstrated as T-cell mediated inflammatory cutaneous disease. It is characterized by linear tendency, usually on the extremities. Its most typical property is the linear arrangement of slightly raised, lichenoid papules. A 28-year-old woman presented with a 3-month history of an asymptomatic linear erythematous violaceous papular lesions on her left abdominal area. Skin biopsy was performed in terms of differential diagnosis from other linear distributions of inflammatory dermatoses. Histopathological examination revealed hyperkeratosis, acanthosis, focal parakeratosis, exocytosis, subbasal dissociation of an area, vacuolar degeneration of the basal membrane, perivascular and lichenoid lymphocytic infiltration. As a result, our case was diagnosed as lichen striatus, clinically and histologically. Topical pimecrolimus ointment twice a day therapy was preferred in the patient.
\end{abstract}

Keywords: Lichen striatus, unusual location, pimecrolimus

\section{Received: February 14, 2018; Accepted: March 30, 2018; Published Online: June 11, 2018}

$\mathrm{L}$ ichen striatus is a rare inflammatory dermatosis that influences mostly children, being rare reports in adults [1]. The pathogenesis is unknown. In addition, lichen striatus is demonstrated as T-cell mediated inflammatory cutaneous disease [2]. It rarely influences adults, and it is characterized by linear tendency, usually on the extremities. Its most typical property is the linear arrangement of slightly raised, lichenoid papules [3]. The linear eruption of inflammatory lesions appears usually over 2 to 3 weeks.

We want to present here case of an adult woman with erythematous violaceous papules on the left abdominal area, diagnosed with lichen striatus by clinical and histopathological correlation.

\section{CASE PRESENTATION}

A 28-year-old woman presented with a 3-month history of an asymptomatic linear erythematous violaceous papular lesions on her left abdominal area (Figure 1). The patient's other skin areas, mucosa, hair and nail examination were normal.

The patient was completely healthy. There was no atopy history in her family and herself. Laboratory tests were normal.

Skin biopsy was performed in terms of differential diagnosis from other linear distributions of inflammatory dermatoses. Histopathological examination revealed hyperkeratosis, acanthosis, focal parakeratosis, exocytosis, subbasal dissociation of an

Address for correspondence: Selami Aykut Temiz, MD., Necmettin Erbakan University Meram School of Medicine, Department of Dermatology, Konya, Turkey

E-mail: aykutmd42@gmail.com,Fax:+903322236204 


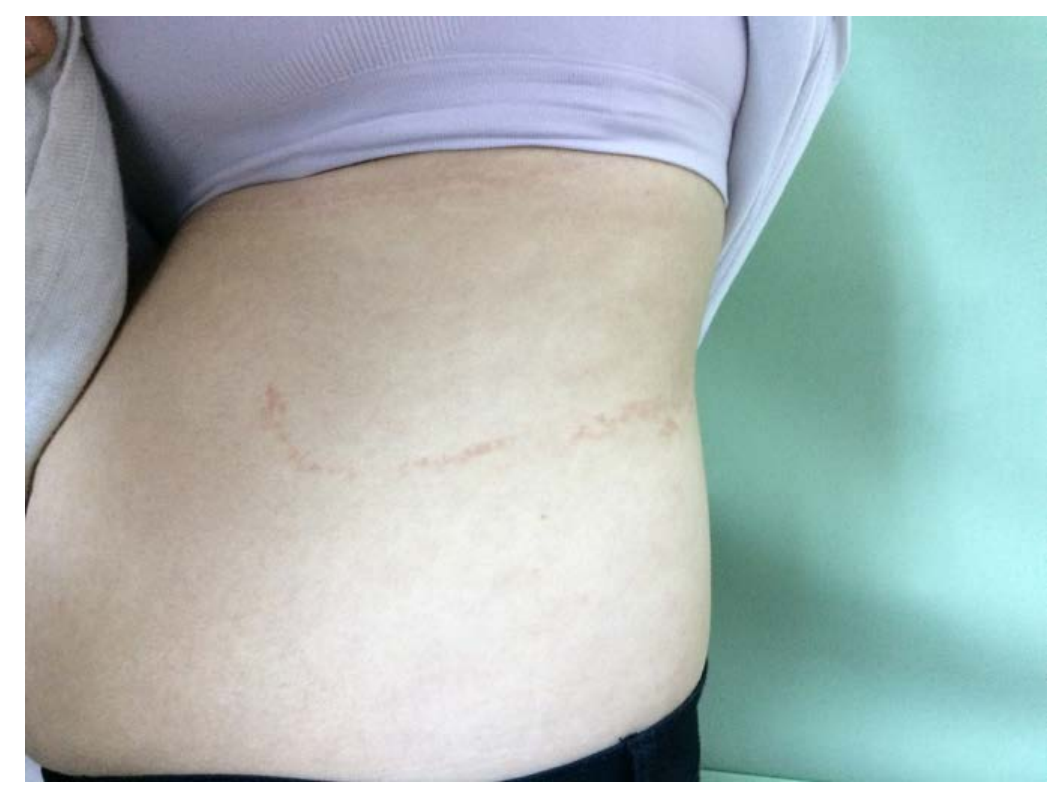

Figure 1. Asymptomatic linear erythematous violaceous papular lesions on her left abdominal area

area, vacuolar degeneration of the basal membrane, perivascular and lichenoid lymphocytic infiltration (Figure 2). The histopathological diagnosis was lichen striatus.

As a result, our case was diagnosed as lichen striatus, based on clinical and histological characteristics. Topical pimecrolimus ointment twice a day therapy was preferred in the patient.

\section{DISCUSSION}

Lichen striatus is defined by erythematous papules with a flattened surface that are constantly scaly in appearance. The lesions are generally solitary and unilateral and have a linear distribution following Blaschko's lines, usually on the extremities [4]. In the pathogenesis, T-cell mediated autoimmune reaction

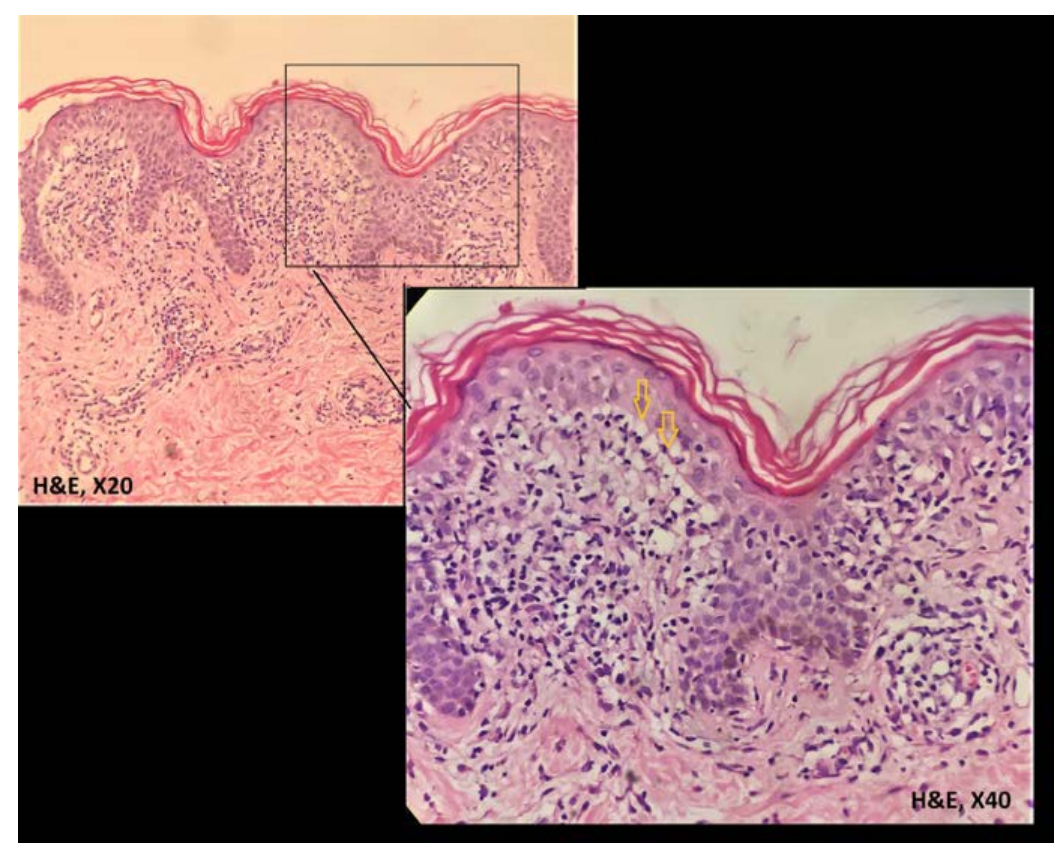

Figure 2. Histopathological examination revealed hyperkeratosis, acanthosis, focal parakeratosis, exocytosis, subbasal dissociation of an area, vacuolar degeneration of the basal membrane, perivascular and lichenoid lymphocytic infiltration. 
against Malpighi cells showing genetic mosaicism and distributed throughout the Blaschko lines is accused [5]. The etiology is mysterious, thought it have been associated with a personal history of atopy. Viral infections, vaccinations, pregnancy, emotional stress, medications, skin trauma, stem cell transplantation and contact dermatitis are the triggering factors [6]. In our case, there is no history of drug use or viral infection that may trigger.

Inflammatory linear lesions have a variety of clinical and histological appearances, and may look like inflammatory linear verrucous epidermal naevus (ILVEN), linear lichen planus, adult blaschkitis, linear morphea, linear psoriasis, linear Darier's disease, linear porokeratosis, verruca plana and linear lichen nitidus [7]. Differential diagnosis of other inflammatory linear lesions is based on histopathology. Histopathologically, lymphocyte-rich, sometimes band-like intense perivascular inflammatory infiltrates, parakeratosis and hyperkeratosis are seen in lichen striatus [8]. All who claim a clear difference between adult blaschkitis and lichen striatus emphasize that lichen striatus predominantly shows papules and histological lichenoid changes [9]. Likewise, histopathology was lichenoidpatern in our case. In addition, adult blaschkitis usually has multiple dermatomal involvements, whereas lichen striatus usually has only one dermatome [10]. In our case, there was only one dermatomal involvement in the same way.

Lichen striatus is very similar clinically and histopathologically to lichen planus. However, histopathological evidence of clustered infiltrates in the hair follicles and the eccrine glands is a distinctive finding for lichen striatus [2]. In our case mononuclear cell infiltration was also detected around hair follicles. Because lichen striatus is a self-limiting dermatosis, the patients may be left to heal spontaneously on treatment. Topical potent steroids are the first choice for treatment in patients with severe itching [11]. In recent years, topical pimecrolimus and topical tacrolimus(topical calcineurin inhibitors) have been successfully used in therapy $[11,12]$. Topical calcineurin inhibitors block interleukin-2 transcription and thus prevent local T lymphocyte activation [13]. Thus, we used topical pimecrolimus in our case.

\section{CONCLUSION}

We think that our case of lichen striatus, which we treated with topical pimecrolimus treatment, was suitable for presentation because of its rare occurrence in adult patients and the rare occurrence of abdominal involvement. We think that further studies are needed about the use of pimecrolimus cream in the treatment of lichen striatus.

\section{Informed consent}

Written informed consent was obtained from the patient for publication of this case report and any accompanying images.

\section{Conflict of interest}

The authors declared that there are no potential conflicts of interest with respect to the research, authorship, and/or publication of this article.

\section{REFERENCES}

[1] Shiohara T, Kano Y: Lichen planus and lichenoiddermatoses. In: Bolognia J, Jorizzo J, Rapini R (eds). Dermatology, 2nd ed., Spain: Mosby-Elsevier, 2008:159-80.

[2] Zhang Y, McNutt NS. Lichen striatus. Histological, immunohistochemical and ultrastructural study of 37 cases. J Cutan Pathol 2001;28:65-71.

[3] Dragos V, Mervic L, Zgavec B. Lichen striatus in a child after immunization. A case report. Acta Dermatovenerol Alp Pannonica Adriat 2006;15:178-80.

[4] Peramiquel L, Baselga E, Dalmau J, Roé E, del Mar Campos M, Alomar A. Lichen striatus: clinical and epidemiological review of 23 cases. Eur J Pediatr 2006;165:267-9.

[5] Campanati A, Brandozzi G, Giangiacomi M, Simonetti O, Marconi B, Offidani AM. Lichen striatus in adults and pimecrolimus: open, offlabel clinical study. Int J Dermatol 2008;47:732-6.

[6] Monteagudo B, Cabanillas M, Suarez-Amor O, Ramirez-Santos A, Alvarez JC, de Las Heras C. [Adult blaschkitis (lichen striatus) in a patient treated with adalimumab]. Actas Dermosifiliogr 2010;101:8912. [Article in Spanish]

[7] Lee MW, Choi JH, Sung KJ, Moon KC, Koh JK. Linear eruptions of the nose in childhood: a form of lichen striatus? Br J Dermatol 2000;142:1208-12.

[8] Muller CS, Schmaltz R, Vogt T, Pfohler C. Lichen striatus and blaschkitis: reappraisal of the concept of blaschkolinear dermatoses. $\mathrm{Br}$ J Dermatol. 2011;164:257-62.

[9] Lipsker D, Stark J, Schneider GA. [Blaschko-linear dermatitis in adulthood (Grosshans-Marot disease) with antinuclear antibodies]. Hautarzt 2000;51:774-7. [Article in German]

[10] Hofer T. Lichen striatus in adults or 'adult blaschkitis'? Dermatology 2003;207:89-92.

[11] Sáez-Rodríguez M, Rodríguez-Martín M, Carnerero-Rodríguez A, 
Sidro-Sarto M, Rodríguez-García F, Cabrera de Paz R, et al. Lichen striatus in an adult successfully treated with pimecrolimus cream. J Eur Acad Dermatol Venereol 2006;20:1140-1.

[12] Stolze I, Hamm H. [Lichen nitidus und Lichen striatus]. Hautarzt 2018;69:121-6. [Article in German]
[13] Vukicevic J, Milobratovic S, Vesic N, Milosevic-Joveic N, Ciric D, Medenica L. Unilateral multiple lichen striatus treated with tacrolimus ointment: a case report. Acta Dermatovenerol Alp Pannonica Adriat 2009; $18: 35-8$. 